\title{
The Natural History of Rheumatic Fever and Rheumatic Heart Disease in the Orient
}

\author{
Hung-Chi Lue, M.D., Chiung-Lin Chen, M.D., Huoyao WeI, M.D., \\ Masahiko Oruni, M.D., Luis M. Mabilangan, M.D., Duangsuda \\ Dharmasakti, M.D., and A. Hanafiah, M.D.
}

\section{SUmmary}

Studies published in the past 10 years suggest that group A streptococcal infections are frequent in the Orient and lead to a high incidence of rheumatic fever (RF) and rheumatic heart disease (RHD). In the present study, streptococcal infections were found to be more prevalent in Japan and Taiwan, whereas RF and RHD were more common and severe in the Philippines, Thailand, and Indonesia, particularly among the socioeconomically less privileged populations. The pattern of childhood RF varied: Carditis was the most common manifestation, occurring in $57 \%$ to $94 \%$ of the patients; polyarthritis was generally atypical and less common in the tropics; chorea minor and erythema marginatum were much more common in Japan, less common in Taiwan and rare in the tropics. $\mathrm{RF}$ recurrences were quite common and led to the development of new carditis, and deterioration or persistence of the preexisting heart disease. The 5 year mortality rates differed greatly, ranging from zero to $42 \%$.

There was disappearance of the heart murmur in $16.5 \%$ to $37.5 \%$ of patients. Such apparent recovery was related to adherence to chemoprophylaxis. The major risk factors adversely affecting survival were the severity of carditis, inadequacy of medical service, non-compliance to chemoprophylaxis, RF recurrence, poor socioeconomic status, and high prevalence of group A streptococci. It is concluded that there is no uniform "Oriental-type" of natural history of RF and RHD. The natural history varies greatly among countries as is true in other parts of the world.

From the Department of Pediatrics, National Taiwan University College of Medicine, Taipei, R. O. China; Department of Pediatrics, Nihon University School of Medicine, Tokyo, Japan; Department of Pediatrics, University of the Philippines College of Medicine, Manila, Philippines; Children's Hospital, Bangkok, Thailand; and Department of Cardiology, University of Indonesia Faculty of Medicine, Jakarta, Indonesia.

Supported by an RF and RHD Prevention Grant from the Cardiac Children's Foundation of the Republic of China.

Reprint request to: Dr. Hung-Chi Lue, Department of Pediatrics, National Taiwan University Hospital, No. 1, Chang-Teh St., Taipei, Taiwan 100, Republic of China.

Presented at the Plenary Session of the VIth Asian-Pacific Congress of Cardiology, Hawaii, U.S.A., October 1976.

Received for publication July 26, 1978. 
Additional Indexing Words:

Rheumatic fever Rheumatic heart disease Orient

R HEUMATIC fever (RF) and rheumatic heart disease (RHD) appeared $\boldsymbol{R}$ to be more prevalent and rampant in some areas of the world, particularly among the developing countries of the tropics. ${ }^{1-5}$ ) The natural history of RF and RHD in each country or area of the world may vary greatly. The related studies and knowledge gathered in the Western countries have been many, thorough and extensive, but those made in the Orient remain very much limited, and, by and large, incomplete. For these reasons, we started, in December 1975, collecting informations concerning the streptococcal infections among populations, and the prevalence and severity of RF and RHD, and their long-term follow-up results from 5 countries, Japan, Taiwan (R.O.C.), the Philippines, Thailand, and Indonesia. Based upon an analysis of the results, the natural history of RF and RHD in the Orient as a whole is thus envisaged, and some of the characteristic features are pointed out and discussed.

\section{Materials AND Methods}

The study area includes Japan, Taiwan, the Philippines, Thailand, and Indonesia. In these 5 countries are living 5 major ethnic groups of the Orient, comprising socioeconomically privileged as well as unprivileged populations. The climate in each country is different, thus the temperate, subtropical, and tropical climates are included. The present study was carried out in 3 steps as follows: Firstly, the authors (Lue, Chen, and Wei) from the National Taiwan University College of Medicine started, in December 1975, analysing their serial clinical studies on 400 patients with RF and RHD admitted consecutively to their University Hospital during the 30 years from 1946 to 1975 . The authors reviewed also their studies on the group A streptococcal infections among patients and school children. The major socioeconomic parameters and the nationwide vital statistics related to RF and RHD in Taiwan were also gathered and analysed. Secondly, the authors invited, in February 1976, 4 pediatric cardiologists to join in this venture, one each from Japan (Okuni, the Nihon University Hospital, Tokyo), the Philippines (Mabilangan, University of the Philippines Hospital, Manila), Thailand (Dharmasakti, Children's Hospital, Bangkok), and Indonesia (Hanafiah, Uneivrsity of Indonesia Hospital, Jakarta). To each of them, a protocol specifically designed by the authors in Taiwan was sent for collection and listing of the published as well as unpublished related information of his home country. Thirdly, all of the important data thus gathered from the 5 countries were put together, analysed and matched. The diagnosis of RF was made based on the revised or modified Jones criteria. ${ }^{6)-8}$ The results of this joint effort form the basis of this report. 


\section{Results}

The socioeconomic status, climate, and prevalence of streptococcal infection and RHD:

The per capita income, literacy rate expressed as the school attendance rate, the population to doctor number ratio, and the yearly average temperature of each country are listed along with the prevalence of streptococcal infection and RHD among elementary school children (Table I). The difference among countries was quite striking. In the order of Indonesia, Thailand, the Philippines, Taiwan, and Japan, the per capita income increased. The literacy rate was the highest in Japan and Taiwan, and the lowest in Indonesia. The population to doctor number ratio was the highest in Indonesia and the lowest in Japan. The yearly average temperature in Japan was the lowest, typical of the temperate climate; that in the northern half of Taiwan belongs to the subtropical; and the rest to the tropical. The prevalence of group A streptococcal infections in Japan, Thailand, Indonesia, and Taiwan was quite different. Highest throat culture positive rates of 16.0 to $29.5 \%$ were observed in Taipei, ${ }^{9,101}$ followed by 9.4 to $15.5 \%$ in Japan, ${ }^{11,12)} 5.0 \%$ in Thailand (Vichitbandhu P, unpublished data), and 1.6\% in Jakarta. ${ }^{13)}$

In 2 Taipei studies, an elevated antistreptolysin O (ASO) titer of 333 T.U. or higher was found in 47.5 to $48.7 \%$ of the school children carrying group A streptococci. ${ }^{9,10}$ ) The ASO titer response in a study among Japanese children was quite similar being 43.5 and $44.8 \%{ }^{12}{ }^{12}$ suggesting that the clinical significance of streptococcal infections in Japan and Taiwan was comparable. A study of the ASO titers in paired serums of 412 Taipei school children carrying group A streptococci revealed that $20.4 \%$ of them were acute or so-called

Table I. Socioeconomic Status, Climate, and Prevalence of Streptococoal Infection and Rheumatic Heart Disease

\begin{tabular}{|c|c|c|c|c|c|c|}
\hline \multirow{2}{*}{ Country } & \multirow{2}{*}{$\begin{array}{l}\text { Per Capita } \\
\text { Income } \\
\text { (US } \$ \text { ) }\end{array}$} & \multirow{2}{*}{$\begin{array}{c}\text { Tempera- } \\
\text { ture } \\
\left({ }^{\circ} \mathrm{C}\right)^{+}\end{array}$} & \multirow{2}{*}{$\begin{array}{c}\text { Literacy } \\
\text { Rates } \\
(\%)^{++}\end{array}$} & \multirow{2}{*}{$\begin{array}{c}\text { Popula- } \\
\text { tion to } \\
\text { Doctor } \\
\text { No. Ratio }\end{array}$} & \multicolumn{2}{|c|}{$\begin{array}{l}\text { Prevalence among } \\
\text { Students }\end{array}$} \\
\hline & & & & & Strep A & RHD* \\
\hline Japan (Tokyo) & $4,405(1975)$ & 11.3 & 99.5 & 859 & $9.4-15.5$ & $0.3-0.4$ \\
\hline Taiwan (Taipei) & $700(1975)$ & 21.6 & 99.5 & 1,733 & $16.0-29.5$ & $1.0-1.8$ \\
\hline Philippines (Manila) & $343(1974)$ & 27.6 & 76.4 & 3,105 & - & - \\
\hline Thailand (Bangkok) & $242(1973)$ & 28.3 & 95.0 & 7,800 & 5.0 & $1.9-2.7$ \\
\hline Indonesia (Jakarta) & $145(1972)$ & 27.3 & 61.0 & 20,000 & 1.6 & $0.3-0.8 * *$ \\
\hline
\end{tabular}


true infections; $30.1 \%$, recent past infections; the rest of $49.5 \%$, chronic infections. ${ }^{10)}$ The antistreptozyme response (Wampole Lab., Dist.), was also made and the result was similar, ${ }^{10)}$ Follow-up throat swab cultures revealed that, in $43 \%$ of them, the carriage of the organism persisted for 4 months or longer. ${ }^{10)}$

Among the patients with symptomatic upper respiratory infection, the throat culture positive rate for the group A streptococci varied widely. It ranged from 3.4 to $14.0 \%$ among Taipei infants and children (unpublished observations). It was higher among patients of all ages: $55.7 \%$ in Japan, ${ }^{14}$ ) $60.3 \%$ in Jakarta (Rilantono LI et al, unpublished observation), and 4.1 to $21.8 \%$ in the Philippines. ${ }^{15}$ It was much lower, 0.3 and $1.1 \%$ among Thai children and adults, respectively (unpublished observations). The RF attack rate among the Taipei school children carrying group A streptococci was once studied, and the result was low. None of the 477 carriers developed RF during a follow-up period of 4 months. ${ }^{10)}$ The RF attack rate following acute streptococcal pharyngitis remains unknown.

The prevalence of RHD among primary and secondary school children varied from 0.3 to 2.7 per thousand (Table I). In Taiwan, it ranged from 1.0 to 1.8 per thousand. ${ }^{16)}$ Serial studies in Osaka, Japan, showed that there was a significant decrease from 1.9 per thousand in 1960 to 0.4 in 1966 , and further down to 0.3 in 1972.17) Recent 2 studies in Thailand revealed higher rates of 1.9 and 2.7 among urban and rural schoolchild populations,

Table II. Age at Onset of First Rheumatic Fever Attacks

\begin{tabular}{|c|c|c|c|c|c|c|}
\hline \multirow{2}{*}{ Area and Year of Study } & \multirow{2}{*}{$\begin{array}{l}\text { Total No. } \\
\text { of Cases }\end{array}$} & \multicolumn{5}{|c|}{ Percent Incidence at Each Age Group (Years) } \\
\hline & & $\leq 2$ & $3-5$ & $6-10$ & $11-15$ & $\geq 16$ \\
\hline \multicolumn{7}{|l|}{ Tokyo, Japan } \\
\hline $1949-61$ & 303 & 3.3 & 15.8 & 59.4 & 21.5 & 0.0 \\
\hline $1961-76$ & 65 & 0.0 & 4.6 & 40.0 & 55.4 & 0.0 \\
\hline $\begin{array}{l}\text { Manila, Philippines } \\
1974\end{array}$ & 201 & 0.0 & $12.9 *$ & 37.8 & 48.3 & 1.0 \\
\hline \multicolumn{6}{|l|}{ Bangkok, Thailand } & 0.0 \\
\hline $197 I-75$ & 85 & 0.0 & 9.4 & 45.9 & 44.7 & 0.0 \\
\hline \multicolumn{7}{|l|}{ Jakarta, Indonesia } \\
\hline $1961-63$ & 47 & 0.0 & 4.3 & 70.2 & 25.5 & 0.0 \\
\hline $1969-72$ & 172 & 1.2 & 6.4 & 44.8 & 47.6 & 0.0 \\
\hline \multicolumn{7}{|l|}{ Taipei, Taiwan } \\
\hline $1946-60$ & 90 & 0.0 & 11.1 & 50.0 & 38.9 & 0.0 \\
\hline $1961-75$ & 344 & 0.0 & 5.2 & 55.5 & 39.3 & 0.0 \\
\hline
\end{tabular}

* Those of 6 years are included into 3-5 years group. 
respectively (Vichitbandhu $\mathrm{P}$, unpublished observations). Lower figures, 0.3 to 0.8 , observed in Indonesia were among urban and well-to-do populations. ${ }^{13), 13 \text { ) }}$

The age at onset of $R F$ :

The age at onset of the first RF attack among the Oriental children varied $\left(\mathrm{X}_{8}^{2}=55.55, \mathrm{p}<0.01\right)$, ranging from $\mathrm{l}$ to 16 years, with a peak at between 6 and 15 years of age (Table II). Few patients below 2 years of age were noted in Japan, and Indonesia, Comparing those of the past with the present series, we noted a tendency that more cases occurred lately at the older age in Japan $\left(X_{2}^{2}=32.87, p<0.01\right)$, and Indonesia ${ }^{17)}\left(X_{2}^{2}=9.56\right.$, $\mathrm{p}<0.01)$.

The hospital statistics of $R F$ and $R H D$ patients:

The number of RF and RHD children admitted yearly to the hospital in each country appears in Fig. 1. The number, expressed as per thousand total pediatric admissions, has changed significantly in Japan and Taiwan. It decreased dramatically in Japan, but increased in Taiwan. No much changes occurred, however, in Thailand and Indonesia.

The ratio of congenital heart disease (CHD) to RHD among hospitalized

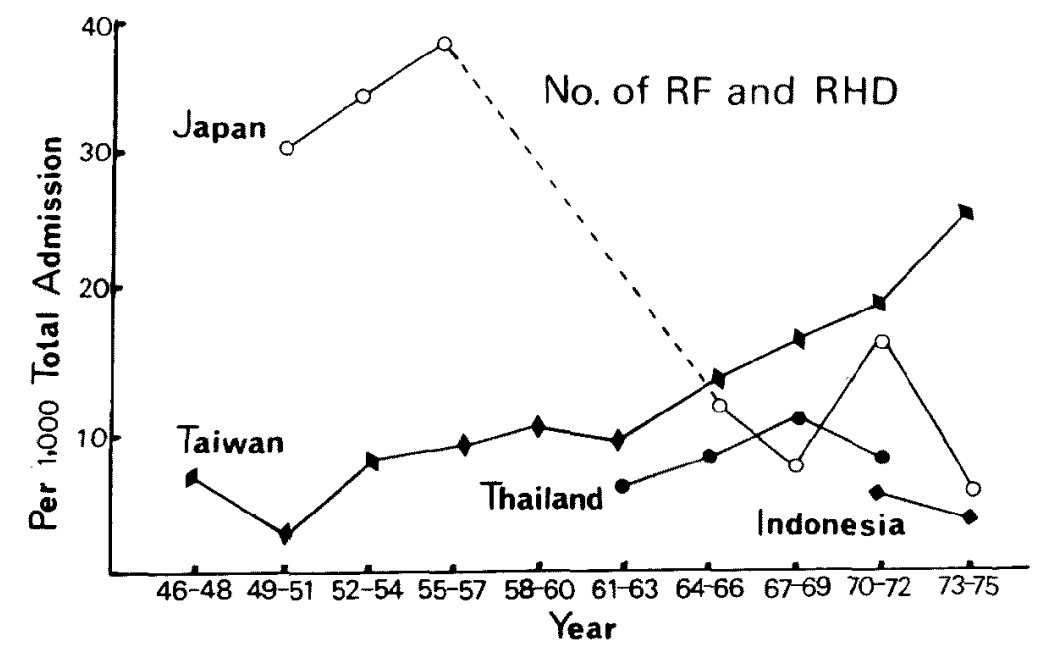

Fig. 1. The number of children with rheumatic fever (RF) and rheumatic heart disease (RHD) admitted ycarly to a major hospital in Japan, Taiwan, Thailand, and Indonesia. The number, expressed as per thousand total pediatric admissions, decreases along with the passage of time most dramatically in Japan, and increases in Taiwan. No much changes occur in the rest of 2 countries. 


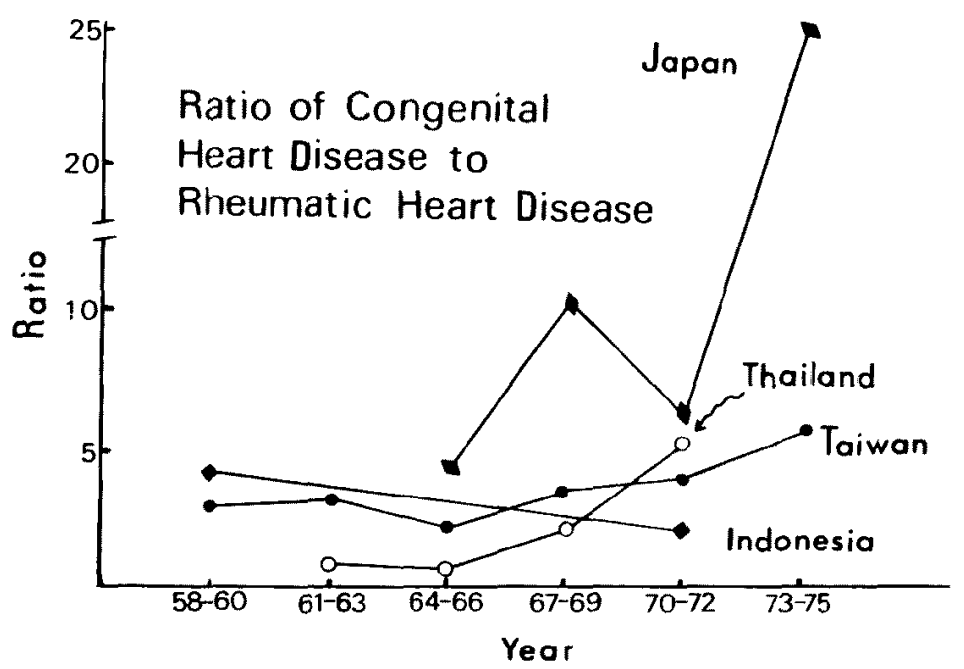

Fig. 2. The ycarly change of the ratio of congenital heart diseasc to rheumatic heart disease among hospitalized children in Japan, Taiwan, Thailand, and Indonesia. The dramatic increase of the ratio in Japan coincides with the marked drop of the prevalence rate of rheumatic fever and rheumatic heart disease.

children was studied and their yearly changes plotted as in Fig. 2. As the incidence of CHD among a given population stays usually unchanged, a change in this ratio at a given hospital may implicate a change in the incidence of RF and RHD. An increase in this ratio occurred most dramatically in Japan, and less so in Taiwan and Thailand suggesting that the occurrence of RF and RHD might have decreased in these areas. A slight decrease was, however, noted in Indonesia. This was, in part, due to a change in their admission policy letting more cases of CHD be admitted directly to the newly established Insititute of Cardiology, bypassing the regular pediatric service.

\section{The major manifestations of $R F$ :}

Among the children with initial or recurrent RF, the most common manifestation was carditis occurring in 57 to $94 \%$ of the cases in different countries. The next most common manifestation was polyarthritis, followed by erythema marginatum, chorea minor, and subcutaneous nodules (Table III). The incidence of carditis varied with different countries being the highest in the Philippines, and lowest in Indonesia. Polyarthritis was less common, and, in general, atypical in the subtropical and tropical zones. The high percentage, such as $66 \%$, reported in the Philippines was exceptional, which was, in part, duc to inclusion of those having occurred in the past. ${ }^{20}$ Erythema marginatum was rather common in Japan, but rare in the tropics, 
Table III. Percent Incidences of the Major Manifestations of Rheumatic Fever in the Orient*

\begin{tabular}{l|c|c|c|c|c|c}
\hline Major Manifestations & $\begin{array}{c}\text { Japan } \\
1958-75 \\
\text { (220 Cases) }\end{array}$ & $\begin{array}{c}\text { Philippines } \\
1974 \\
\text { (208 Cases) }\end{array}$ & $\begin{array}{c}\text { Thailand } \\
1961-75 \\
(325 \text { Cases })\end{array}$ & $\begin{array}{c}\text { Indonesia } \\
1969-72 \\
(170 \text { Cases })\end{array}$ & $\begin{array}{c}\text { Taiwan } \\
\text { (400 Cases) }\end{array}$ & P** \\
\hline Palyarthritis & $55.0 \%$ & $66.0 \% \%^{+}$ & $35.7 \%$ & $39.8 \%$ & $33.0 \%$ & $<0.01$ \\
Erythema marginatum & 16.4 & 0.5 & 0.3 & 1.7 & 6.0 & $<0.01$ \\
Chorea minor & 9.5 & 0.9 & 2.5 & 3.5 & 5.7 & $<0.01$ \\
Subcutaneous nodules & 3.6 & 5.0 & 1.5 & 0.1 & 2.2 & $<0.01$ \\
Carditis & 65.9 & 94.0 & 60.0 & 57.0 & 84.0 & $<0.01$
\end{tabular}

* Among children with initial or recurrent rheumatic fever. ** Chi square test. + Inclusive of the cases who developed polyarthritis in the past.

such as Indonesia, the Philippines, and Thailand. Chorea minor was, likewise rare in all tropical countries. The mode of the appearance of arthritis, carditis, and chorea, singly or in combination was studied in a series of 165 cases of first RF attacks in Taiwan. Arthritis occurred as an isolated manifestation in $15.2 \%$, carditis in $59.4 \%$, and chorea in $2.4 \%$. Arthritis and carditis occurred together in $19.4 \%$, chorea and carditis in $1.2 \%$, and arthritis and chorea in $2.4 \%$. The manifestations encountered in the past and present series of Taiwan and Japan were compared. Along with the passage of time, the incidence of arthritis decreased both in Japan and Taiwan, from 60.6 to $42.9 \%$, and from 52.2 to $27.4 \%$, respectively. That of chorea also decreased from 10.7 to $7.1 \%$, and from 12.2 to $3.9 \%$, respectively. The incidence of carditis remained almost unchanged in Japan, but increased considerably, from 66.7 to $89 \%$, in Taiwan. Erythema marginatum and subcutaneous nodules kept occurring at approximately the same rates.

The valvular lesions:

The valvular changes observed among the Oriental children varied $\left(\mathrm{X}_{12}^{2}=28.79, \mathrm{p}<0.01\right)$. They were mostly confined to the mitral and aortic valves (Table IV). The mitral valve was involved as a single lesion in 87.1 to $92.8 \%$, and the aortic valve in 1.6 to $6.8 \%$ of the cases. It is of interest to note that aortic insufficiency was particularly common in Japan as compared with the rest of the countries studied. ${ }^{19), 21}$ ? The percent incidence of pure mitral stenosis in each country was strikingly similar, being encountered only in 3 to $5 \%$ of the cases. Very rarely, the trcicuspid valve was involved together with the mitral and/or aortic valves.

The natural recovery of $R H D$ :

The cardiac murmur disappeared and the heart size returned to normal 
Table IV. Valvular Lesion and Their Percent Distribution in Children with Rheumatic Heart Disease

\begin{tabular}{|c|c|c|c|c|c|}
\hline Valvular Lesion & $\begin{array}{c}\text { Japan } \\
\text { (163 Cases) }\end{array}$ & $\begin{array}{l}\text { Philippines } \\
\text { (196 Cases) }\end{array}$ & $\begin{array}{l}\text { Thailand } \\
\text { (178 Cases) }\end{array}$ & $\begin{array}{c}\text { Indonesia } \\
\text { (203 Cases) }\end{array}$ & $\begin{array}{c}\text { Taiwan } \\
\text { (307 Cases) }\end{array}$ \\
\hline Mitral valve & 87.1 & 88.0 & 92.8 & 87.2 & 88.4 \\
\hline Insufficiency & (42.9) & $(44.0)$ & $(62.4)$ & $(57.1)$ & (46.8) \\
\hline Stenoinsufficiency & $(39.3)$ & $(39.0)$ & $(27.0)$ & $(27.1)$ & $(37.6)$ \\
\hline Stenosis & (4.9) & $(5.0)$ & $(3.4)$ & $(3.0)$ & $(4.0)$ \\
\hline Aortic valve & 6.8 & 2.0 & 1.7 & 4.4 & 1.6 \\
\hline Insufficiency & $(6.8)$ & $(2.0)$ & $(1.7)$ & $(3.9)$ & $(1.6)$ \\
\hline Stenoinsufficiency & $(0.0)$ & $(0.0)$ & $(0,0)$ & $(0.5)$ & $(0.0)$ \\
\hline Mitral and aortic valves & 6.1 & 3.0 & 5.0 & 7.9 & 8.9 \\
\hline Others & 0.0 & 7.0 & 0.5 & 0.5 & 1.1 \\
\hline All types (Percent) & 100.0 & 100.0 & 100.0 & 100.0 & 100.0 \\
\hline
\end{tabular}

Table V. Natural Recovery of Carditis Observed in Japan, Thailand, and Taiwan

\begin{tabular}{|c|c|c|c|c|c|c|}
\hline \multirow[b]{2}{*}{ Cardiac Status at Start } & \multicolumn{2}{|c|}{ Japan } & \multicolumn{2}{|c|}{ Thailand } & \multicolumn{2}{|c|}{ Taiwan } \\
\hline & $\begin{array}{l}\text { No. Cases } \\
\text { Followed }\end{array}$ & $\begin{array}{l}\text { No. Cases } \\
\text { Recovered }\end{array}$ & $\begin{array}{l}\text { No. Cases } \\
\text { Followed }\end{array}$ & $\begin{array}{l}\text { No. Cases } \\
\text { Recovered }\end{array}$ & $\begin{array}{l}\text { No. Cases } \\
\text { Followed* }\end{array}$ & $\begin{array}{l}\text { No. Cases } \\
\text { Recovered }\end{array}$ \\
\hline No Cardiomegaly & & & & & & \\
\hline MI, minimal & 19 & 15 & 4 & 4 & 7 & 6 \\
\hline MI, definite & 10 & 0 & 48 & 16 & 5 & 4 \\
\hline AI, definite & 10 & 0 & 2 & 2 & 0 & 0 \\
\hline With cardiomegaly & & & & & & \\
\hline MI & & & 59 & 0 & 42 & 13 \\
\hline MIMS & & & 12 & 1 & 10 & 3 \\
\hline MIAI & & & & & 1 & 0 \\
\hline AI & & & & & 2 & 0 \\
\hline $\begin{array}{l}\text { With failure and/or } \\
\text { pericarditis }\end{array}$ & & & & & & \\
\hline MI & I & 0 & 143 & 26 & 54 & 8 \\
\hline MIMS & & & 41 & 2 & 36 & 3 \\
\hline MIAI & & & & & 12 & $8^{+}$ \\
\hline AI & & & & & 2 & 0 \\
\hline Others & & & & & 19 & 0 \\
\hline $\begin{array}{l}\text { Total } \\
\text { (Percent) }\end{array}$ & $\begin{array}{c}40 \\
(100,0)\end{array}$ & $\begin{array}{l}15 \\
(37.5)\end{array}$ & $\begin{array}{l}309 \\
(100.0)\end{array}$ & $\begin{array}{l}51 \\
(16.5)\end{array}$ & $\begin{array}{l}190 \\
(100,0)\end{array}$ & $\begin{array}{l}45 \\
(23.7)\end{array}$ \\
\hline
\end{tabular}

AI : Aortic insufficiency. AS : Aortic stenosis. MI : Mitral insufficiency. MS : Mitral stenosis. * Follow-up period: 1 to 16 (average 5.4) years. + Of the murmurs, all lost in 1, MI only in 4 and AI only in 3 cases. 
in a considerable number of patients. The available data from Japan, Thailand, and Taiwan, as listed in Table $\mathrm{V}$, showed that natural recovery of the carditis occurred in $37.5 \%, 16.5 \%$, and $23.7 \%$ of the children with definite RHD, respectively, during a follow-up period of 1 to 16 (average 5.4) years. The overall recovery rate varied with different countries $\left(\mathrm{X}_{\mathrm{c}}^{2}=2416.08, \mathrm{p}<\right.$ 0.01 ), but was closely related to the cardiac status at the start of treatment. The milder the carditis, the more likely was the murmur to disappear. The time needed for the disappearence of murmurs ranged from 1 month to 9 years (Table VI). It varied with different countries $\left(\mathrm{X}_{8}^{2}=19.16, \mathrm{p}<0.05\right)$. In more than half $(54.5 \%)$ of the cases, the murmur disappeared within the first year following medical treatment. In $10 \%$ of the cases, the recovery was effected as late as 6 to 9 years after the treated attack of carditis.

The evolution and acquisition of cardiac murmurs:

Very limited was the information available for the analysis in this regard. A follow-up study of 159 cases of RF and RHD in Taiwan showed that, of the 15 cases who had no heart disease at the start, 3 developed subsequently a cardiac murmur (Table VII): 1 who had had chorea minor developed mitral stenosis in 15 years; 2 others, 1 chorea and 1 arthritis, acquired later the clinical

Table VI. Time Needed for Disappearance of Cardiac Murmurs

\begin{tabular}{l|c|c|c|c|c|c}
\hline \multicolumn{1}{c|}{ Area } & $\begin{array}{c}\text { No. Cases } \\
\text { with } \\
\text { Murmur Lost }\end{array}$ & \multicolumn{3}{|c|}{ Time Needed for Disappearance of Murmurs (Year) } \\
\hline Japan & 15 & 1 & $1-2$ & $2-4$ & $4-6$ & $6-9$ \\
Thailand & 50 & 10 & 1 & 1 & - & 3 \\
Taiwan & 45 & 20 & 15 & 3 & - & 2 \\
\hline Total & 110 & 8 & 4 & 7 & 6 \\
(Percent) & $(100.0)$ & $(54.5)$ & $(21.8)$ & $(7.3)$ & $(6.4)$ & $(10.0)$
\end{tabular}

Table VII. Evolution and Acquisition of Cardiac Murmurs (Dept. of Pediatrics, National Taiwan Univ. Hospital, Taiwan)*

\begin{tabular}{l|c|c|c|c}
\hline $\begin{array}{c}\text { Cardiac Status } \\
\text { at Start }\end{array}$ & $\begin{array}{c}\text { No. Cases } \\
\text { Followed* }\end{array}$ & \multicolumn{2}{|c|}{ New Valvular Disease at End } \\
\hline No heart disease & 15 & Pure MS & Pure MI & AI and Others \\
MI only & 108 & $2^{+}$ & 2 & 0 \\
MIMS & 36 & 1 & 0 & 3 \\
\hline Total & 159 & $4^{+}$ & 0 & 1 \\
\hline
\end{tabular}

* Length of follow-up : 1 to 16 (average 5.4) years. + One case stayed in chemoprophylaxis. Al: Aortic insufficiency. MI : Mitral insufficiency. MS : Mitral stenosiss. 
evidences of mitral insufficiency. Of the 108 children, who had had mitral insufficiency at start, 2 progressed to pure mitral stenosis: 1 developed typical mitral stenosis in one and half years despite the regular benzathine penicillin chemoprophylaxis; the other developed mitral stenosis in 4 years under irregular chemoprophylaxis following 2 episodes of retreated RF recurrence. Among these 108 cases, a new acquisition of aortic insufficiency occurred in 3 cases who proved to have 1 or 2 retreated recurrences. Among the 36 cases who had had mitral stenoinsufficiency at start, one progressed to pure mitral stenosis, and another acquired aortic insufficiency.

The attacks of $R F$ recurrences:

RF recurrence occurred very commonly among the Oriental children. This is reflected in the observations that high percentages of RF patients, such as $12.2 \%$ of 345 patients (Thailand), $63.6 \%$ of 33 cases (Indonesia), and $46.8 \%$ of 310 cases (Taiwan), were being treated at the hospitals for their recurrent attacks. The long-term chemoprophylaxis program for the RF recurrence was, for some reasons, not popular in the Orient. The compliance status to a long-term (6-7 years) chemoprophylaxis program utilizing benzathine penicillin was studied among 665 children with RF and RHD in Taipei and Bangkok. The results showed that those who were able to stay in the program were merely $30 \%$ of the cases; stay-in non-compliant, $15 \%$; drop-out reenter, $4 \%$; drop-out no return, $51 \%$. A long-term follow-up study in Taiwan showed that, during the first 5 years, $43(17.1 \%)$ of the living 251 patients developed RF recurrences; during the second 5 years, $14.4 \%(17 / 118)$; and during the third 5 years, $3.5 \%$ (1/29). The recurrence rate was lower, 1.68 per 100 patient-years, among the stay-in compliant group; and higher, 8.07 per 100 patient-years, in the stay-in non-compliant group. The over-all RF recurrence rates observed in Thailand and Taiwan were quite comparable being 3.28 and 4.51 per 100 patient-years, respectively.

\section{Bacterial endocarditis:}

Bacterial endocarditis occurred in $31(2.2 \%)$ of 1,433 patients followed up in Thailand, Taiwan, Japan, and Indonesia. It occurred in $5(1.1 \%)$ of 456 patients receiving long-term chemoprophylaxis, and in $26(2.7 \%)$ of 977 cases without long-term prophylaxis.

\section{The mortality due to $R F$ and $R H D$ :}

It was recognized that rheumatic carditis was more often severe and florid leading to fatality at younger ages in the tropical areas (Table VIII). The fatality occurred at or before the age of 44 years in more than $80 \%$ of the 
Table VIII. Age at Death from Rheumatic Fever and Rheumatic Heart Disease

\begin{tabular}{|c|c|c|c|c|c|c|}
\hline \multirow{2}{*}{ Area } & \multirow{2}{*}{ Year of Study } & \multirow{2}{*}{$\begin{array}{l}\text { No. Cases } \\
\text { Observed }\end{array}$} & \multicolumn{4}{|c|}{ Age at Death (Percent Incidence) } \\
\hline & & & $<15$ & $15-24$ & $25-44$ & $>45$ \\
\hline Japan & 1973 & $3,647^{*}$ & 0.3 & 2.4 & 16.9 & 80.4 \\
\hline Philippines & $1946-57$ & $141 * *$ & 10.0 & 30.0 & 40.0 & 20.0 \\
\hline Thailand & $1961, \quad 1963-72$ & $284^{+}$ & 33.4 & 43.3 & 15.5 & 7.8 \\
\hline Taiwan & $1957-74$ & $18,544^{*}$ & 7.8 & 6.3 & 15.9 & 70.0 \\
\hline
\end{tabular}

Table IX. Mortality Rate of Rheumatic Fever and Rheumatic Heart Disease Patients

\begin{tabular}{|c|c|c|c|c|c|c|}
\hline \multirow[b]{2}{*}{$\begin{array}{c}\text { Area and Year } \\
\text { of Study }\end{array}$} & \multicolumn{3}{|c|}{ Without Chemoprophylaxis } & \multicolumn{3}{|c|}{ With Chemoprophylaxis } \\
\hline & $\begin{array}{l}\text { No. Case } \\
\text { Followed }\end{array}$ & $\begin{array}{l}\text { Length of } \\
\text { Follow-up } \\
\text { (Year) }\end{array}$ & $\begin{array}{l}\text { Mortality } \\
\text { (Percent) }\end{array}$ & $\begin{array}{l}\text { No. Case } \\
\text { Followed }\end{array}$ & $\begin{array}{l}\text { Length of } \\
\text { Follow-up } \\
\text { (Year) }\end{array}$ & $\begin{array}{l}\text { Mortality } \\
\text { (Percent) }\end{array}$ \\
\hline Japan & & & & & & \\
\hline $1944-1954$ & 83 & $1-10$ & 16.9 & - & - & - \\
\hline $1963-1976$ & - & - & - & 69 & $1-12$ & 0.0 \\
\hline Thailand & & & & & & \\
\hline $1960-1965$ & 434 & 6 & 10.4 & - & - & - \\
\hline $1970-1975$ & 317 & 6 & 3.5 & - & - & - \\
\hline Indonesia & & & & & & \\
\hline $1969-1974$ & 50 & 5 & 42.0 & - & - & - \\
\hline Taiwan & & & & & & \\
\hline $1946-1960$ & 49 & $1-15(5.0)$ & 24.5 & - & - & - \\
\hline $1961-1975$ & 101 & $1-15(8.4)$ & 28.7 & 131 & $1-15(5.5)$ & 3.1 \\
\hline
\end{tabular}

( ): Figures in parentheses denote the average length of follow-up.

cases in the Philippines and Thailand, while it occurred only in less than 20 to $30 \%$ of the cases in Japan and Taiwan $\left(\mathrm{X}_{9}^{2}=1685.18, \mathrm{p}<0.01\right)$. The mortality rate varied among the 4 countries studied (Table IX). In Japan and Taiwan series, we noted high mortality rates among those without prevention, and low ones among those protected from RF recurrence, documenting the important contribution of the long-term chemoprophylaxis $\left(\mathrm{X}_{\mathrm{c}}^{2}=41.33\right.$. $p<0.01)$. A highest mortality rate of $42 \%$ was noted in Indonesia among those receiving no chemoprophylaxis (Sumantri D et al, unpublished observation). Nationwide statistics showed that the annual death rates in Taiwan, Japan, and Thailand were quite different in the 1950s, but they became quite close in the 1970s (Fig. 3). In Thailand, it remained, however, surprisingly fixed throughout the past 2 decades. 


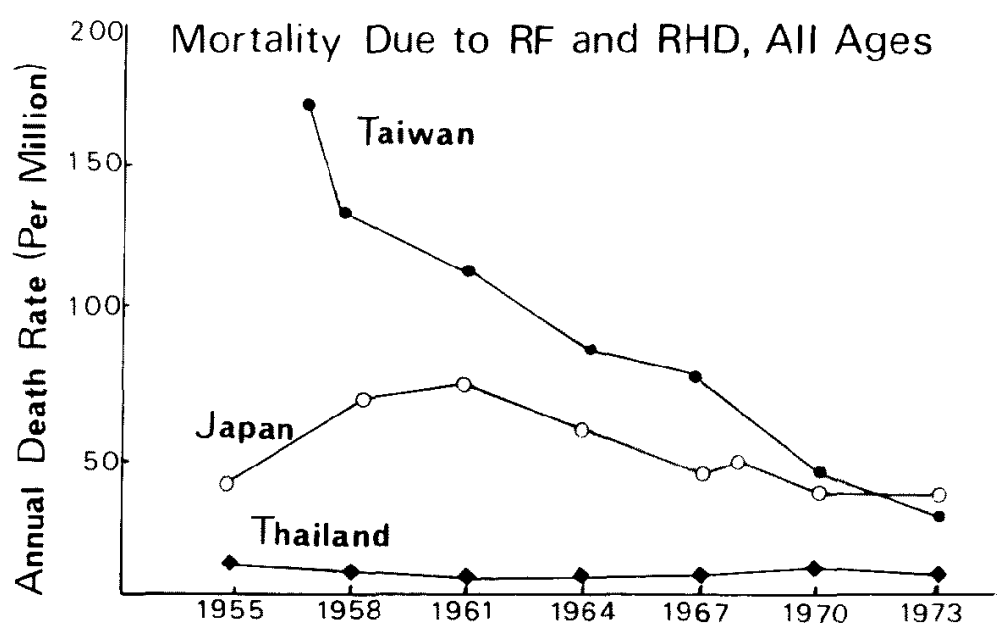

Fig. 3. The yearly change of the number of annual deaths due to rheumatic fever (RF) and rheumatic heart disease (RHD) per million population. The death rates in Japan, Taiwan, and Thailand are quite different in the 1950s, but become close in the 1970s.

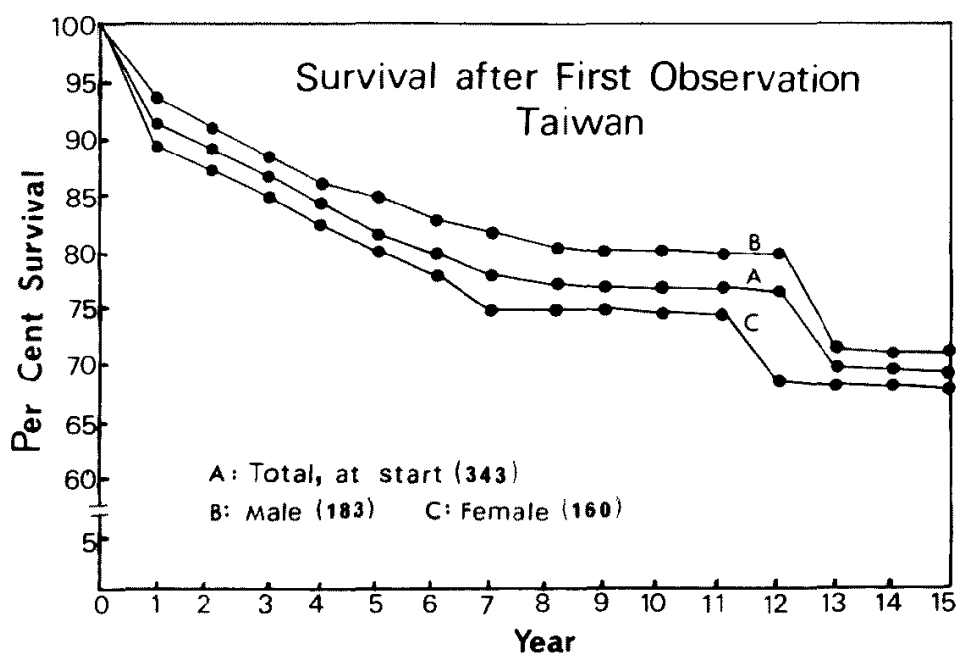

Fig. 4. A survival curve plotted by an actuarial method based on a Taiwan study. Nearly $10 \%$ of the 343 cases died in the first year following treatment; another $10 \%$ died during the subsequent 5 years. Males survive longer.

The survival and its major risk factors:

A long-term follow-up study on 343 cases in Taiwan showed that, the highest mortality rate occurred in the first year following treatment, during which nearly $10 \%$ of the patients died as seen in the survival curve plotted by an actuarial method (Fig. 4). Another $10 \%$ died during the subsequent 5 


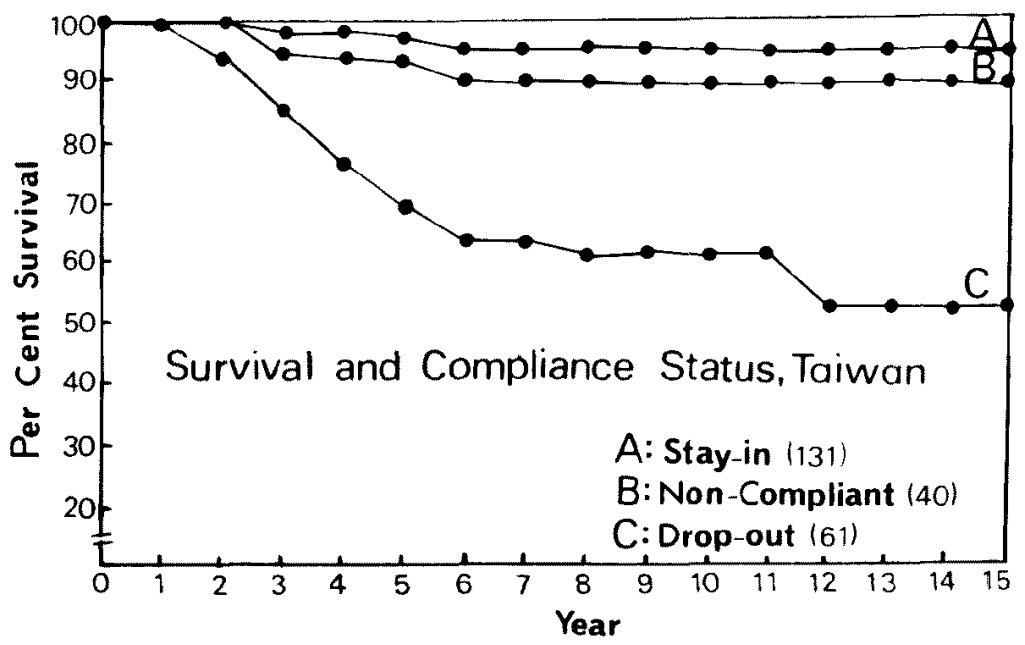

Fig. 5. A survival curve plotted by an actuarial method based on a Taiwan study on 232 cases, of whom 131 stayed in the long term chemoprophylaxis program; 40 stayed but not compliant; and 61 dropped out. More than $90 \%$ of those who had stayed in the program survived the entire followup period.

years. Seventy-six percent of the 343 cases survived for 10 years. The survival was clearly in favor of males. The worst survival rate was observed among those who had preexisting heart disease. We documented again that there was a close association between the group A streptococcal infection and the natural history of RF and RHD. As seen in Fig. 5, the chance of survival increased by the compliance to long-term chemoprophylaxis. More than $90 \%$ of the 131 cases who stayed in the chemoprophylaxis survived the entire follow-up period.

\section{Discussion}

The present study confirmed that RF and RHD occurred widely in the Orient. In Japan, their incidence was once high, but has declined and remained low nowadays. In Taiwan, the incidence could be high in the past years, and seems to be decreasing each year, as judged from the marked and steady reduction of the nationwide annual death rates. In Thailand, the available data suggest that there has been no significant change yet in the morbidity and mortality caused by the disease. The situations in the Philippines and Indonesia remain to be studied. Our observations suggest, therefore, that in the Orient, the disease continues to be a problem, less impressing in the temperate zones and more so in the tropics. 
Among the 5 countries surveyed, there were apparent regional differences in terms of clinical presentation and course of the disease. Erythema marginatum occurred rarely among the tropical countries studied, as was reported in India. ${ }^{22)}$ Polyarthritis, which is a common occurrence in Japan and other Western temperate countries, appears to be atypical and less common in the subtropical and tropical countries. The mode of the appearance of RF major manifestations observed in Taipei was different to those observed in the Western developed countries. ${ }^{23), 24}$ The overall clinical features thus observed in Taiwan appear to be the inbetween of those observed in the temperate developed and tropical developing countries. The present study suggests that the regional distinctions observed within the Orient are likewise those observed in other parts of the world. ${ }^{21,25), 26)}$ Sanyal et $\mathrm{al}^{27}$ ) in a recent prospective study of the clinical profile of RF in India stated, however, that the first attacks of RF in North India closely resembled the spectrum prevalent in developed countries. Shaper ${ }^{2}$ has suggested that the different ecology of the disease in each area could be responsible for the apparent regional distinctions. It seems mandatory that a further prospective study is needed for clarification of this issue.

Long-term chemoprophylaxis is very crucial and helpful, as proved in the present study, to natural healing of the rheumatic carditis and reduction of the mortality. The present study has revealed also that, in the tropics, the prevalence of detectable group A streptococcal throat infection is low, yet RHD is common and florid, while, in the temperate countries the streptococcal infections are common, yet RHD is now unusual. These conflicting findings remain to be proved and explained by further studies. It is of interest to assume that a low RF attack rate, such as we found in Taipei may also be the case in Japan, where the streptococcal infections proved common, yet the RHD prevalence kept decreasing. Quinn et $\mathrm{al}^{28)}$ and Brownell et $\mathrm{al}^{29)}$ reported that $20 \%$ of their $\mathrm{RF}$ patients represented recurrences. $\mathrm{RF}$ recurrences observed in the Orient are significantly more common than those in the United States. ${ }^{281,29)}$ It is a very likely possibility that the high prevalence and seriousness of RF and RHD existing in many places of the Orient can be attributed largely to frequent RF recurrences, leading to persistence and deterioration of the valve lesions. In the 5 countries we surveyed, the long-term prophylaxis program has remained far from being popular. In no place was it enforced by law, or widely carried out by practitioners. The programs remain as the limited practice at the major hospitals. The reasons leading to non-compliance, as disclosed in a study at Taipei, are manifold, such as apparent recovery from their sufferings with resumption of normal activities, cram sessions at school, inadequacy of the medical delivery system, 
and undue phobia of the penicillin anaphylaxis among practitioners. ${ }^{30}$ The overall disapperance rate of the murmurs or socalled natural recovery rate of RHD we observed in Taipei, Bangkok, and Japan was, therefore, significantly lower than those reported in the US and UK cooperative studies. ${ }^{31 \text {, }}$ A Taipei study revealed that the murmur disappeared in $31 \%$ of the 116 cases who stayed in the prophylaxis, but disappeared only in $12 \%$ of the 74 cases who were non-compliant or dropped out (unpublished observation). RF recurrences have thus dictated a poor survival. The female preponderance in both occurrence and mortality we observed in Taipei agrees well with that reported by other investigators. ${ }^{23), 321,33)}$ We know that multiple factors, such as poverty, illiteracy, inadequate medical service, decreased host resistance to infection, ecology of the streptococcus, and rheumatogenecity of the organism rather than the geographical factor and climate are concerned in the natural history of RF and RHD. Amongst this array of risk factors, we believe that the unprivileged socioeconomic condition and the inadequate medical delivery system are the most important ones governing the natural history of the disease. These 2 key factors act together as a common denominator in the Orient as well as in other parts of the world.

\section{REFERENGES}

1. Strasser T: Rheumatic fever and the health of population. Jap Circulat J 39: 174, 1975

2. Shaper AG: Cardiovascular disease in the tropics-I, rheumatic heart. Brit Med J 3:683, 1972

3. Shiokawa Y: Epidemiology of rheumatic fever and rheumatic heart disease in Japan. Jap Circulat J 39: 185, 1975

4. Ilyas M: Secondary prevention of rheumatic heart disease in Pakistan. Jap Circulat J 39 : 194, 1975

5. Roy SB: Challenge of juvenile mitral stenosis in India. Jap Circulat J 39: 198, 1975

6. American Heart Association: Committee on standards and criteria for prognosis of care. Jones criteria (modified) for guidance in the diagnosis of rheumatic fever. Mod Concept Cardiovasc Dis 24: 291, 1955

7. American Heart Association: Ad hoc Committee to revise the Jones criteria (modified) of the council on rheumatic fever and congenital heart disease. Jones criteria (revised) for guidance in the diagnosis of rheumatic fever. Circulation 32:664, 1965

8: Lue HC: The diagnostic criteria of rheumatic fever in Chinese children. J Formosan Med Assoc 73: 255, 1974

9. Lee CH, Lue HC, Liu JL, Hsieh RP: A survey on the beta-hemolytic streptococcal infection among school children in Taipei. Acta Pediatrica Sin 17: 1, 1976

10. Lue HC, Lee CH, Hsich RP, Liu JL, Chen SH, Chen GL: Prevention of rheumatic heart disease. Identification and treatment of streptococcal infections in school children. J Formosan Med Assoc 76: 1, 1977

11. Okuni $M$ et al: Rheumatic fever and tonsils. Therapy 46: 124, 1964 (in Japanese)

12. Kawakita S, Takeuchi T, Uemura Y, Onishi T, Saito K, Nagami H, Watanabe T, Watanabe T: Group A streptococcal infections as related to rheumatic fever. Jap Heart J 17: 592, 1976 
13. Sulianto G'PB, Ranti ISF: A cardiological survey on 2943 school children from Djakarta. Pediatrica Indonesiana 5: 925, 1965

14. Committee Report: Chemoprophylaxis in rheumatic heart disease, Japan, 1st Report, Vol 11,1972 (in Japanese)

15. Limson BM: Consolidation of Philippine data on streptococcal pharyngitis and rheumatic heart disease. University of East J Medicine p 21-28, July-December, 1968

16. Lue HC, Ghen GM, Hsu JY, Chen CL, Wei HY: Prevalence of rheumatic heart disease in the young in northern Taiwan. Jap Circulat J 39: 188, 1975

17. Takashina $\mathrm{YN}$ et al: Heart disease and its mass control. Pediatric Diagnosis and Treatment 34: 273,1971 (in Japanese)

18. Saleh RM, Amir S: A cardiological survey of elementary school children in Surabaya. Majalah Kedokteran Surabaya's Medical J 4: 119, 1972 (in Indonesia)

19. Hanafiah A, Liem TK, Ranti ISF: Heart disease in infancy and childhood in Jakarta. Pediatrica Indonesiana 5: 952, 1965

20. Mabilangan LM, Mojica BA Jr: A study on rheumatic fever and rheumatic heart disease among 208 Filipino children. Philippine J Cardiol 2: 4, 1974

21. Okuni M: Clinical Aspects of Rheumatic Fever. Chiu-Gai Medical Publisher, Tokyo, 1969 (in Japanese)

22. Roy SB: Challenge in the diagnosis of rheumatic activity. Indian Pediatrics 10: 571, 1973

23. Perry CB: The natural history of acute rheumatism. The Sumleian lecture of the Royal College of Physicians, 1969. Ann Rheum Dis 28: 471, 1969

24. Mayer FE, Doyle EF, Herrera L, Bronnell KD: Decining severity of first attack of rheumatic fever. Am J Dis Child 105: 146, 1963

25. Berry JN: Prevalence survey for chronic rheumatic heart disease and rheumatic fever in northern India. Brit Heart J 34: 143, 1972

26. Rheumatism Review Subcommittee of the American Rheumatism Association: Twenty-First Rheumatism Review. Review of the American and English literature for the years 1971 and 1972. New York, the Arthritis Foundation, p 657, 1974

27. Sanyal SK, Thaper MK, Ahmed SH et al: The initial attack of acute rheumatic fever during childhood in North India. A prospective study of the clinical profile. Circulation 49: 7 , 1974

28. Quinn RW, Federspiel CF: The incidence of rheumatic fever in metropolitan Nashville. 1963-1969. Am J Epidemiol 99: 273, 1973

29. Brownell KD, Bailen-Rose F: Acute rheumatic fever in children. Incidence in a borough of New York City. JAMA 224: 1593, 1973

30. Lue HC, Chen CL, Wei HY: Some problems in long-term prevention of streptococcal infection among children with rheumatic heart disease in Taiwan. Jap Heart J 17: 550, 1976

31. Rheumatic Fever Working Party, M.R.C. and American Heart Association: The natural history of rheumatic fever and rheumatic heart disease. Ten-year report of a cooperative clinical trial of ACTH, cortisone and aspirin. Circulation 32: 457, 1965

32. Negus RM: Rheumatic fever in Western Fiji. The female preponderance. Med J Aust 2: 251,1971

33. Al-Bahrani IR, Thamer MA, Al-Omeri MM, Al-Naaman YD: Rheumatic heart disease in the young in Iraq. Brit Heart J 28: 824, 1966 